\title{
Integração do Pensamento Computacional às Disciplinas da Educação Básica: uma Proposta de Aplicativo para Professores
}

\author{
Barbara Morais \\ Universidade Federal Rural de \\ Pernambuco \\ Recife, Pernambuco, Brasil \\ bebelkinp458@gmail.com
}

\author{
Rozelma França \\ Universidade Federal Rural de \\ Pernambuco \\ Recife, Pernambuco, Brasil \\ rozelma.franca@ufrpe.br
}

\author{
Taciana Pontual Falcão \\ Universidade Federal Rural de \\ Pernambuco \\ Recife, Pernambuco, Brasil \\ taciana.pontual@ufrpe.br
}

A educação básica no Brasil é fundamentada na Base Nacional Comum Curricular (BNCC) [1], que em 2018 introduziu as habilidades e/ou competências para o termo Pensamento Computacional (PC) na disciplina de matemática. Autores como Zanetti et al. (2016) mostram resultados de práticas educacionais que estimulam e envolvem o PC como primórdio do avanço do ensino tecnológico [4]. Porém, apesar dos diversos estudos que discutem o PC, o termo ainda é desconhecido para muitos professores da educação básica. Neste contexto, esta pesquisa tem como principais objetivos, analisar como o PC pode ser aplicado de forma multidisciplinar através de práticas e ferramentas que disseminem esse conhecimento, e compreender a perspectiva do professor sobre as diferentes ferramentas que envolvam práticas relacionadas aos pilares do PC.

Existem várias ferramentas e materiais que buscam apoiar a disseminação do PC na educação básica [2], como por exemplo, o sertão.bit, um livro jogo que alia narrativas, cultura e PC [3]. A disponibilidade dessas ferramentas facilita a aplicação das atividades, porém ainda é um desafio para os professores integrá-las às suas áreas específicas de ensino. Há uma carência de ferramentas que provêm atividades que claramente conectam o PC a cada área.

Para compreender melhor a familiaridade dos professores com o PC e as suas expectativas, e assim guiar o desenvolvimento de uma ferramenta que os apoie, foi realizada uma pesquisa com professores do ensino básico da rede estadual de Pernambuco, através de um questionário online que possuía três grupos de perguntas sobre: uso de ferramentas educacionais tecnológicas; práticas interdisciplinares; e conhecimentos sobre PC. Os resultados guiaram a prototipação de um aplicativo que integram o PC às diversas disciplinas.

Dada a dificuldade da situação de pandemia e o período de final de ano, obtivemos apenas 07 respostas aos questionários até o momento. Os resultados parciais indicam que: $71,5 \%$ dos professores usam com frequência ferramentas tecnológicas educacionais para o planejamento e/ou execução de suas atividades; $71,4 \%$ não conhecem o termo PC; e $42,9 \%$ conhecem o termo PC mas não sabem abordá-lo em suas atividades. Por unanimidade, todos afirmaram que sentem necessidade de mais ferramentas tecnológicas para os auxiliarem, e $85,7 \%$ usariam, caso lhes fosse oferecida, uma

Fica permitido ao(s) autor(es) ou a terceiros a reprodução ou distribuição, em parte ou no todo, do material extraído dessa obra, de forma verbatim, adaptada ou remixada, bem como a criação ou produção a partir do conteúdo dessa obra, para fins não comerciais, desde que sejam atribuídos os devidos créditos à criação original, sob os termos da licença CC BY-NC 4.0.

EduComp'21, Abril 26-30, 2021, Jataí, Goiás, Brasil (On-line)

(c) 2021 Copyright mantido pelo(s) autor(es). Direitos de publicação licenciados à

Sociedade Brasileira de Computação (SBC). ferramenta educacional tecnológica que abordasse o PC de maneira multidisciplinar.

Ao compreender as perspectivas dos professores extraídas dos dados, confirmamos a demanda por ferramentas de apoio na realização de atividades que integrem o PC. Assim, desenvolvemos um protótipo de aplicativo que apresenta um conjunto de atividades relacionadas ao PC, de forma integrada às diversas disciplinas, a ideia é o professor disponha de um recurso que reúna diversas atividades práticas, plano de aula, links para ambientes externo. No aplicativo o professor poderá cadastrar atividades, sendo este recurso facilitador para ampliar o número de atividades e dar autonomia ao profissional, pois ele poderá adaptar à proposta da prática a sua área.

Além da pretensão de uma avaliação por especialistas em testes de usabilidade, o aplicativo considera a rotina dos professores e suas colocações em diferentes aspectos, por exemplo: tempo de aula, planejamento, recursos disponíveis, portanto, artefatos voltados para professores são significativos no âmbito do planejamento educacional.

A disponibilização de uma ferramenta para auxiliar os professores no processo de ensino-aprendizagem, gera uma expectativa diante dos resultados de ser bem aceita entre esses profissionais, visto que, todas as narrativas e dados iniciais revelam uma tendência no aumento do interesse por partes dos professores para usufruir das habilidades do PC em sua área. Nesse contexto, essa ferramenta acaba contribuindo para a divulgação dos termos tecnológicos, pois frequentemente se restringem ao ambiente computacional sendo fortemente necessário no ambiente do ensino básico e aplicável em diversas áreas.

\section{REFERÊNCIAS}

[1] BNCC. 2018. Base Nacional Comum Curricular: Educação é a base. Disponível: http://basenacionalcomum.mec.gov.br/images/BNCC_EI_EF_110518_ versaofinal_site.pdf. Acesso em: 1 jun. 2019.

[2] Christian Puhlmann Brackmann. 2017. Desenvolvimento do pensamento computacional através de atividades desplugadas na educação básica. Ph.D. Dissertation.

[3] Rozelma França and Patrícia Tedesco. 2019. Sertão. Bit: Um livro-jogo de difusão do pensamento computacional. In Anais dos Workshops do Congresso Brasileiro de Informática na Educação, Vol. 8. 278.

[4] Humberto Zanetti, Marcos Borges, and Ivan Ricarte. 2016. Pensamento computacional no ensino de programação: Uma revisão sistemática da literatura brasileira. In Brazilian Symposium on Computers in Education (Simpósio Brasileiro de Informática na Educação-SBIE), Vol. 27. 21. 